\title{
Chronic liquid nutrition feeding affects blood pressure, heart and kidney morphology, and serum lipid profile in Wistar rats
}

\author{
Livia Mikuska $^{1^{*}}$, Michaela Vrabcova ${ }^{2 *}$, Lubica Horvathova ${ }^{1}$, Jana Osacka ${ }^{1}$, Ivan Varga ${ }^{2}$ \\ and Boris Mravec ${ }^{1,3}$ \\ ${ }^{1}$ Institute of Experimental Endocrinology, Biomedical Research Center, Slovak Academy of Sciences, Dubravska cesta 9, \\ 84505 Bratislava, Slovak Republic \\ ${ }^{2}$ Institute of Histology and Embryology, Faculty of Medicine, Comenius University in Bratislava, Sasinkova 4, 81108 Bratislava, \\ Slovak Republic \\ ${ }^{3}$ Institute of Physiology, Faculty of Medicine, Comenius University in Bratislava, Sasinkova 2, 81372 Bratislava, Slovak Republic
}

\begin{abstract}
We determined the effect of chronic liquid nutrition (Fresubin) intake in different developmental stages on the cardiovascular and renal system of male Wistar rats. Body weight, water intake and blood pressure were periodically measured. Selected serum and urine biochemical parameters reflecting metabolic and homeostatic changes after Fresubin intake were investigated as well. Heart and kidney weight, diameter of cardiomyocytes, diameter and length of cardiomyocyte nuclei, wall thickness of thoracic aorta, the diameter and the area of renal corpuscles and serum and urine biochemical parameters were assessed at the end of experiment. We showed that Fresubin intake differently affects the investigated morphological and biochemical parameters in rats and this effect was dependent on the developmental stage when Fresubin was provided. Importantly, we have shown that Fresubin-induced elevation of blood pressure is a reversible phenomenon and it is independent of weight gain and subsequent development of obesity.
\end{abstract}

Key words: Blood pressure - Heart - Kidney - Liquid nutrition - Rat - Water intake

\section{Introduction}

Palatable liquid nutrition Ensure (Abbott Laboratories) commonly used in human medicine was employed also in several animal studies focused on diet-induced obesity (Levin and Keesey 1998; Levin 1999; Archer et al. 2005; Archer et al. 2007; Marco et al. 2009). It was shown that feeding rats with palatable liquid nutrition represents an effective animal model to study the mechanisms of diet-induced obesity (Archer et al. 2005). Levin et al. (1998) showed that addition of Ensure to high-fat diet produced sustained excessive food intake in rats, leading to weight gain and obesity. We have previously proved that the complete substitution of pelleted chow diet by a palatable liquid diet, specifically Fresubin,

Correspondence to: Boris Mravec, Institute of Physiology, Faculty of Medicine, Comenius University in Bratislava, Sasinkova 2, 81372 Bratislava, Slovak Republic

E-mail: boris.mravec@fmed.uniba.sk

${ }^{*}$ Both authors have contributed equally to this work induced the development of marked obesity in the Wistar rats (Mikuska et al. 2013).

As the current trend of excessive soft drinks intake in human population is associated with alarmingly high prevalence of obesity not only in adults, but also in children and adolescents, the animal models of liquid nutrition feeding represent an important tool to investigate the pathological mechanisms in the development of human obesity (Ludwig et al. 2001; Malik et al. 2006) and related diseases, such as diabetes, stroke, and essential hypertension (Dobrian et al. 2000). The mechanisms that link obesity and elevated blood pressure are not yet fully understood. Hypothalamic inflammation, activation of renin-angiotensin system, sympathetic nervous system, hyperleptinemia, as well as dyslipidaemia, and hypertriglyceridaemia play an important role (Dobrian et al. 2000; Baba et al. 2007).

The kidney plays a major role in the control of cardiovascular function and blood pressure (Rahmouni et al. 2005), therefore it is not surprising, that the worldwide epidemic of obesity-initiated metabolic syndrome is associated with 
high risk of renal damage (Bagby 2004). Several studies using animal models investigated the effect of moderate or high-fat diet and diet-induced obesity on hypertension, functional and structural changes in the kidney. It was demonstrated that obesity-prone rats exhibit hypertension, hypercholesterolemia, hyperinsulinemia, renin-angiotensin system activation, and increased renal oxidative stress (Dobrian et al. 2004; Boustany et al. 2005). Jiang et al. (2005) found increased renal lipid accumulation and glomerulosclerosis in diet-induced obese mice (Jiang et al. 2005). Altunkaynak et al. (2008) observed histopathological changes such dilatation, tubular defects, inflammation, and connective tissue enlargement of the kidney in high-fat fed obese rats. However, it is necessary to note that several studies did not find any changes in blood pressure or cardiac abnormalities after moderate or high-fat feeding (Carroll et al. 2006; Nascimento et al. 2011).

Based on the above mentioned facts, we investigated the effect of chronic liquid nutrition intake on blood pressure, selected biochemical parameters in serum and urine, the size of cardiomyocytes, renal corpuscles (Malpighian bodies), and the wall thickness of the thoracic aorta (tunica intima and tunica media) in rats.

\section{Material and Methods}

Animals

Male Wistar rats with single dams were purchased from Charles River (Germany). After weaning rats were housed
4 per cage and maintained under controlled conditions (12 h light/dark cycle, lights on at 6:00 a.m., ambient temperature $22 \pm 1^{\circ} \mathrm{C}$ and $55 \pm 10 \%$ humidity). All measurements were performed between 8:00-12:00 h. All external noises or any other stressful stimuli of the animals have been strictly avoided. The experiments were carried out in accordance with the Council Directive 2010/63EU of the European Parliament and the Council of $22^{\text {nd }}$ September 2010 on the protection of animals used for scientific purposes.

\section{Experimental design and diets}

After weaning (at the age of 21 days) rats were divided into 4 experimental groups based on the type of provided diet: 1) control group (CON, $n=20)$ received standard pelleted rat chow during the whole study (5 months); 2) liquid nutrition group (LN, $n=20$ ) received Fresubin during the whole study (5 months); 3) liquid nutrition juvenile group (LNJ, $n=20$ ) received Fresubin until $90^{\text {th }}$ day of age and then transferred to pelleted rat chow until the end of the study; and 4) liquid nutrition adult group (LNA, $n=20$ ) received pelleted rat chow until $90^{\text {th }}$ day of age and then transferred to Fresubin until the end of the study (Fig. 1). All the groups were provided with tap water ad libitum during the whole experiment. Body weight, food and water intake were regularly measured throughout the study.

The gross composition of the diets were as follows: a) standard chow diet contains $88.79 \mathrm{~g}$ of dry substance with $23.04 \mathrm{~g}$ of protein, $2.72 \mathrm{~g}$ of fat, and $8.49 \mathrm{~g}$ of carbohydrate

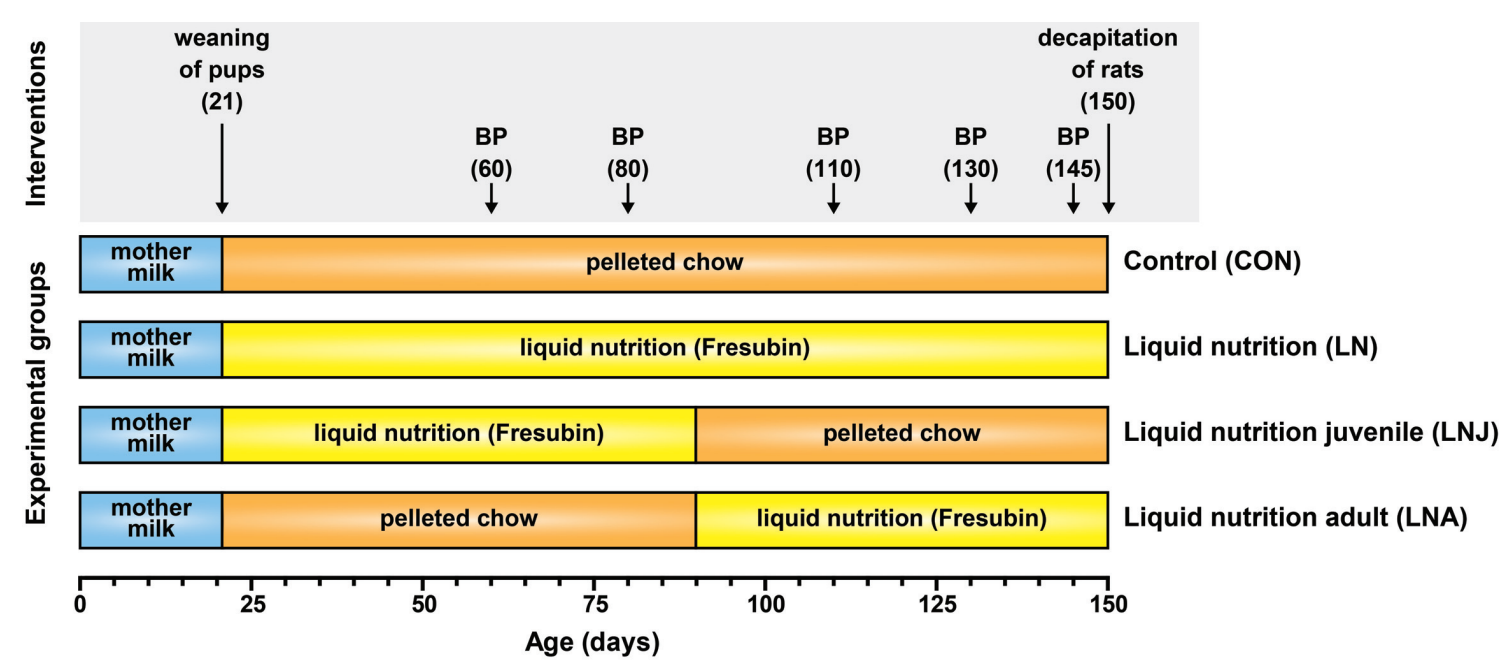

Figure 1. A schematic illustration of the experimental design. At the age of $21^{\text {st }}$ days pups were weaned and randomly separated into control group (CON) - fed with pelleted chow for the entire study; liquid nutrition group (LN) - fed by Fresubin for the entire study; liquid nutrition juvenile group (LNJ) - fed 70 days by Fresubin and then 60 days by pelleted food; liquid nutrition adult group (LNA) - fed 70 days by pelleted chow and then 60 days by Fresubin. At the age of $60^{\text {th }}, 80^{\text {th }}, 110^{\text {th }}, 130^{\text {th }}$, and $145^{\text {th }}$ blood pressure (BP) was measured. At the end of the study rats were perfused and cardiovascular and renal tissues were removed for further morphometric analyses. 
and $11.21 \mathrm{ml}$ of water in $100 \mathrm{~g}$; b) Fresubin liquid nutrition contains $84 \mathrm{ml}$ of water and $23.9 \mathrm{~g}$ of dry substance with $3.8 \mathrm{~g}$ of protein, $3.4 \mathrm{~g}$ of fat and $13.8 \mathrm{~g}$ of carbohydrate in $100 \mathrm{ml}$ (for details see Mikuska et al. 2013).

\section{Obesity assessment}

Body weight gain was recorded periodically using the electronic weighing scale. At the end of the study 32 rats (8 from each experimental group) were deeply anesthetized by sodium pentobarbital $(50 \mathrm{mg} / \mathrm{kg}$ b.w. intraperitoneally, Spofa, United Pharmaceutical Works, Czech Republic) and abdominal circumference and the length of the rats were determined. Parameters were determined by the measuring tape, abdominal circumference $(\mathrm{cm})$ was measured around the anterior abdomen and length $(\mathrm{cm})$ was measured as a distance between nasal and anal region (Mamikutty et al. 2014). The body weight and body length were used to determine the following anthropometrical parameters: Body mass index $(\mathrm{BMI})=$ body weight $(\mathrm{g}) /$ length ${ }^{2}\left(\mathrm{~cm}^{2}\right)$ and Lee index (Bernardis and Patterson $1968)=$ cube root of body weight $(\mathrm{g}) /$ naso-anal length (cm) (Novelli et al. 2007).

\section{Water intake}

Water intake was calculated by deducting the remainder of the water from the amount offered to the animals the day before. Moreover, total water intake was calculated as the sum of tap water and the water contained in Fresubin (represented by 75\%) or pelleted chow (represented by $12 \%)$.

\section{Blood pressure measurement}

The measurements were carried out in a noise-protected room. The whole procedure during the experiment was carried out by the same person to whom the animals were accustomed. Blood pressure was measured non-invasively in conscious rats using the tail-cuff method (ADInstruments). Blood pressure measurement started in 60 days old rats, when we could achieve a sufficient compression of their tails due the tail cuff. Before this date the blood pressure was not analyzed due to the insufficient thickness of rats' tails. The tails of the rats were heated with an infra-red lamp to avoid vasoconstriction conditioned by cold. The measurement was accompanied by a short-term compression of the tissue surrounding the tail vein and interruption of blood flow. After subsequent analysis the systolic and diastolic blood pressure were simply established. The procedure was carried out in each animal in pre-determined time intervals between 8:00 and 12:00 a.m., 5 times during the whole study, at the age of $60,80,110,135$ and 145 days. Five different records from each rat were taken to calculate the mean systolic and diastolic blood pressure. The measurements themselves were preceded by a 1 month lasting period of habituation and adaptation, simulating the whole procedure (animals inserted into the holder with attached tail cuff) to avoid the exertion of the results by stress.

\section{Blood collection and tissue preparation}

At the end of the study (age 150 days) rats were randomly sacrificed by decapitation ( $n=12$ per group) or transcardial perfusion ( $n=8$ per group). Blood samples were obtained directly during decapitation or immediately before perfusion ( $3 \mathrm{ml}$ of blood were taken from the left heart ventricle by $5 \mathrm{ml}$ syringe and collected into test tubes).

Immediately after sacrification the kidneys, heart, and thoracic aorta were removed and weighed. The left heart ventricle was dissected from the heart. The weight of organs was calculated in terms of organ weight/body weight (\%) (Ndisang and Jadhav 2010).

\section{Blood lipid profile, serum and urine biochemical parameters}

Blood samples were kept $30 \mathrm{~min}$ at room temperature and afterwards centrifuged for $20 \mathrm{~min}$ at $3000 \times g$ at $4^{\circ} \mathrm{C}$. In the obtained serum the concentrations of total cholesterol, triglycerides (TGL), very low density cholesterol (VLDL), creatinine and total serum proteins were determined by spectrophotometric methods (Dimension RxL Max device). Concentrations of sodium and potassium ions in serum were analyzed by indirect potentiometry (Dimension RxL Max device).

Samples of 24-hour urine were collected from each rat. Levels of creatinine, proteins, sodium, and potassium were determined (Dimension RxL Max device).

\section{Histological processing of heart, thoracic aorta, and kidneys}

Thirty two rats ( 8 from each experimental group) were deeply anesthetized by sodium pentobarbital $(50 \mathrm{mg} / \mathrm{kg}$, Spofa, United Pharmaceutical Works, Czech Republic, $500 \mathrm{mg}$, intraperitoneally) and transcardially perfused with $50 \mathrm{ml}$ of saline followed by $250-300 \mathrm{ml}$ of fixative solution containing 4\% paraformaldehyde (Sigma-Aldrich, Germany) in $0.1 \mathrm{M}$ phosphate buffer ( $\mathrm{PB}, \mathrm{pH}$ 7.4). The kidneys, heart, and aorta were rapidly removed and post-fixed in the same fresh fixative solution at $4^{\circ} \mathrm{C}$ overnight and afterwards stored in sodium azide (Sigma Chemical Ltd., St. Louis, MO, USA) until processed. Paraffin blocks were prepared, $5 \mu \mathrm{m}$ thick sections were obtained using rotary microtome (Leica RM 2235) and stained with hematoxylin and eosin (heart and thoracic aorta) and with the Gomori's impregnation method modified by Lilie (kidneys). 
The quantitative morphometric measurements were performed using Axio Scope.A1 (Carl Zeiss) microscope and AxioCamERc5s S/N MKG 1890 (Carl Zeiss) camera at $200 \times$ magnification for the kidneys, $400 \times$ magnification for the heart, and $100 \times$ magnification for the thoracic aorta. The evaluation of sections was performed by employing ZEN Widefield-UI Automation Mode 2011 (Carl Zeiss) software for Windows. Quantitative assessment was performed from the captured images on the computer screen scored in a blinded manner and mean values were calculated. Diameter of cardiomyocytes was measured along a line intercepting the cell nucleus in 100 cells per animal (Farah et al. 2009). Length of the cardiomyocyte nucleus was measured along a line that intercepted the respective nucleus in 100 cells per animal (Noszczyk-Nowak et al. 2009). The wall thickness of the aorta (tunica intima and tunica media) was measured and the mean values were calculated from 10 measurements per each rat. For the quantitative assessment of mean area and mean diameter of renal corpuscles randomly 100 corpuscles per animal were measured.

\section{Statistical analysis}

All statistical analyses were performed using GraphPad Prism program version 5.02 (GraphPad Software, San Diego CA, USA). Statistical analysis of the data was performed by one-way ANOVA (factor group) followed by Bonferroni's post hoc test to determine significant differences in anthropometrical parameters used for obesity assessment, heart and kidney morphology, as well as serum

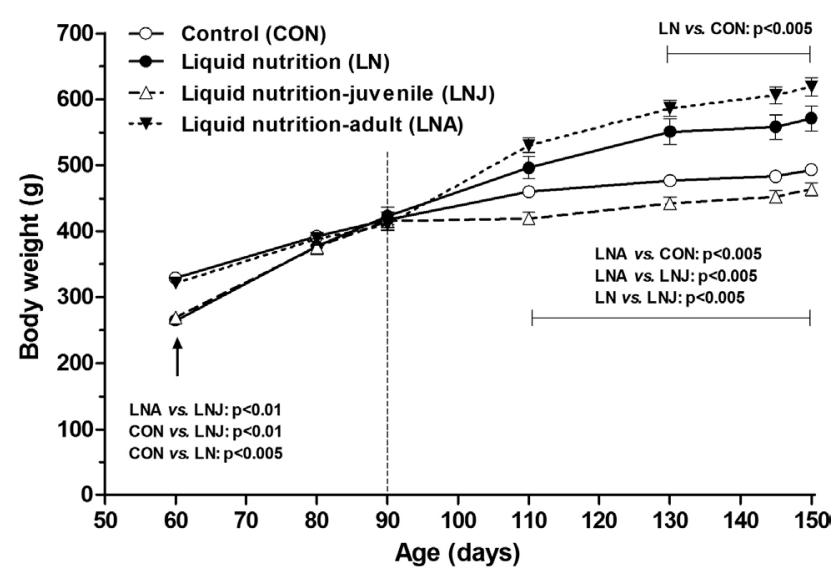

Figure 2. Body weight of rats fed with pelleted chow (CON), liquid nutrition (LN), liquid nutrition in juvenility (LNJ), or liquid nutrition in adulthood (LNA). Dashed line represents time when diet of LNJ and LNA groups was changed. Each value is expressed as mean \pm SEM ( $n=20$ for each group). Statistical significance between groups (Bonferroni post-tests) indicated in the graph. and urine biochemical parameters. Two-way ANOVA with factors time and diet followed by Bonferroni's post hoc test was used to determine significant differences in body weight, water intake, and blood pressure. The results are expressed as means \pm SEM and represent an average of $8-20$ animals. The $p<0.05$ was taken as indicative of statistical significance for the tests.

\section{Results}

\section{Body weight}

Two-way ANOVA analysis revealed that body weight was significantly influenced by applied diet $(\mathrm{F}=77.04, p<$ $0.0001)$, time $(\mathrm{F}=239.1, p<0.0001)$ as well as their interaction ( $\mathrm{F}=9.823, p<0.0001$; Fig. 2 ).

At the beginning of the experiments the Wistar rats from all four experimental groups had similar body weights. However, after the start of Fresubin consumption we observed that the Fresubin fed LN and LNJ rats exhibit lower body weight whereas the pelleted chow fed CON and LNA rats exhibited higher body weight. The differences between Fresubin and pelleted chow fed groups began to be statistically significant around the age of 35 days (for details see Mikuska et al. 2013). The 60 days old Fresubin fed rats (LN and LNJ) fed by Fresubin immediately after weaning had significantly lower body weight compared to the pelleted chow fed control (CON vs. LN $p<0.005$, CON vs. LNJ $p<0.01$ ) and LNA groups (LNA $v s$. LN $p<0.01$, LNA $v s$. LNJ $p<0.01$, Fig. 2). When the rats reached the age of 80 respectively 90 days, their body weight was very similar, without significant differences between the 4 experimental groups. After 90 days of age, the body weight of LN group as well as that of LNA group which switched from pelleted chow to Fresubin began to increase and at the age of 110 days the difference in body weight between the animals fed with Fresubin after the $90^{\text {th }}$ day and animals fed with pelleted chow reached statistical significance (age 110 till 150 days: LN $v s$. LNJ $p<0.005$, LNA $v s$. CON $p<0.005$, LNA $v s$. LNJ $p<0.005$; age 130 till 150 days: LN vs. CON $p<0.005$, Fig. 2). Since this time the Fresubin fed rats (LN and LNA) were gaining body weight till the end of the experiment and became obese whereas the body weight of the chow fed rats (CON and LNJ) plateaued (Fig. 2).

The anthropometrical parameters used to identify obesity at the end of the study showed that in the LN and LNA rats increased fat accumulation in the abdominal region that led to significantly increased abdominal circumference (LN vs. CON $p<0.01$, LN vs. LNJ $p<0.05$, LNA $v s$. CON $p<0.005$, LNA vs. LNJ $p<0.005$, Fig. 3A). Similar results confirming obesity development were obtained after the calculation of BMI (LN vs. CON $p<0.01, \mathrm{LN} v s$. LNJ 
$p<0.01$, LNA $v s$. CON $p<0.01$, LNA $v s$. LNJ $p<0.005$, Fig. $3 \mathrm{~B}$ ) as well as the Lee index (LN vs. CON $p<0.01, \mathrm{LN}$ $v s$. LNJ $p<0.05$, LNA $v s$. CON $p<0.05$, LNA $v s$. LNJ $p<$ 0.01, Fig. 3C).
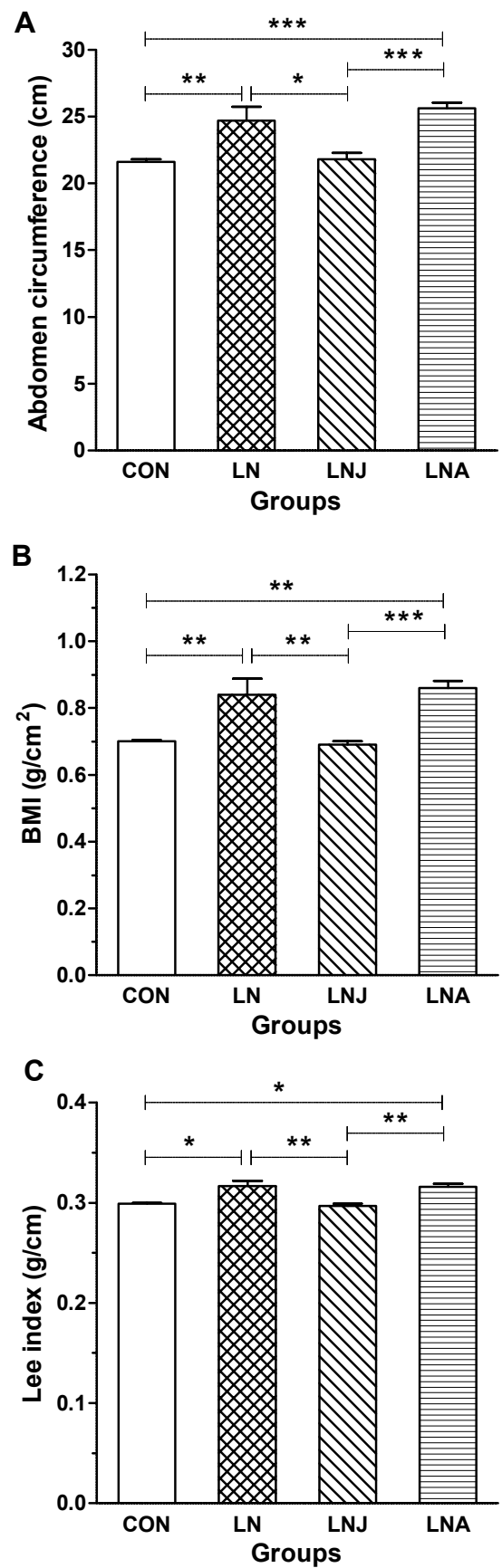

Figure 3. Abdomen circumference (A), body mass index (B), and Lee index $(\mathbf{C})$ of rats fed with pelleted chow $(\mathrm{CON})$, liquid nutrition (LN), liquid nutrition in juvenility (LNJ), or liquid nutrition in adulthood (LNA). Each value is expressed as mean $\pm \operatorname{SEM}(n=8$ for each group). Statistical significance between groups: ${ }^{*} p<0.05$, ${ }^{* *} p<0.01,{ }^{* *} p<0.005$.

\section{Water intake}

Statistical analysis confirmed the effect of applied diet $(\mathrm{F}=$ $6498, p<0.0001)$ and time $(\mathrm{F}=121.6, p<0.0001)$ as well as the effect of their interaction $(\mathrm{F}=284.9, p<0.0001)$ on the water intake of the experimental groups (Fig. 4A,B).

In Fresubin fed rats (LN, LNJ, and LNA groups) a significant decrease of tap water intake was detected during Fresubin consumption ( $p<0.05$, Fig. 4A). However, after the recalculation of total water intake (tap water + water contained in Fresubin and tap water + water contained in pelleted chow) an opposite result was found ( $p<0.05$, Fig. 4B).

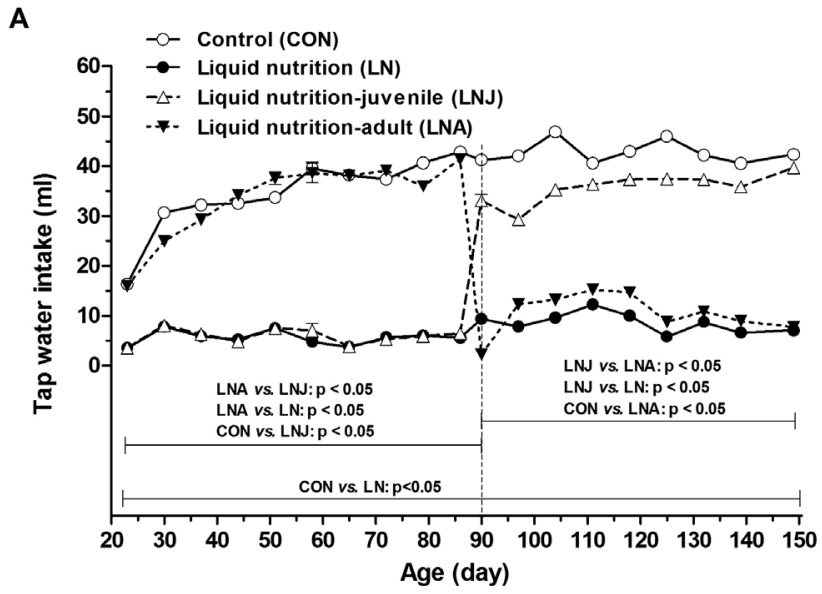

B

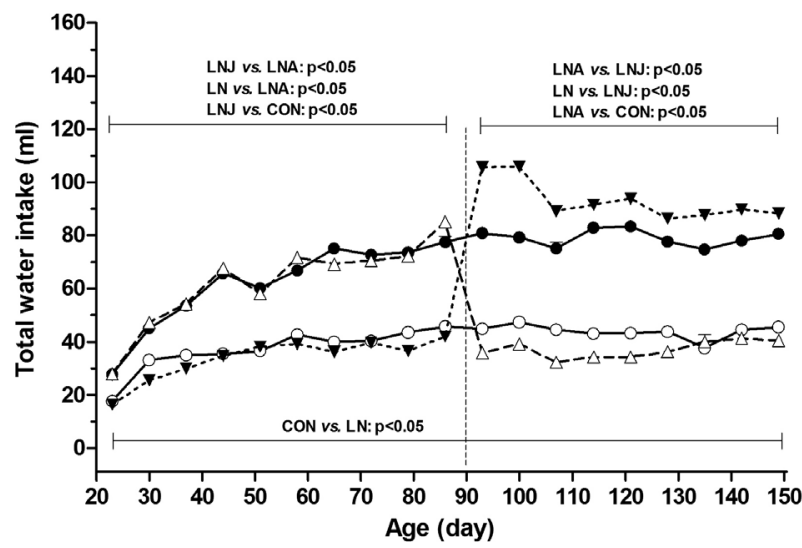

Figure 4. Tap water intake (A) and total water intake (B) of rats fed with pelleted chow (CON), liquid nutrition (LN), liquid nutrition in juvenility (LNJ), or liquid nutrition in adulthood (LNA). Dashed line represents time when diet of LNJ and LNA groups was changed. Total water intake was calculated as a sum of tap water + water in Fresubin or tap water + water in pelleted chow. Each value is expressed as mean $\pm \operatorname{SEM}$ ( $n=20$ for each group). Statistical significance between groups (Bonferroni post-tests) indicated in the graph. 


\section{Blood pressure}

Systolic (SBP) and diastolic (DBP) blood pressure was significantly influenced by the applied $\operatorname{diet}(\mathrm{F}=13.88, p<$ $0.0001)$ as well as time alone $(\mathrm{F}=2.890, p=0.0223)$, and by the interaction of both factors $(\mathrm{F}=5.748, p<0.0001$; Fig. $5 \mathrm{~A}, \mathrm{~B})$.

When compared to the chow fed CON rats, the liquid nutrition fed LN rats showed significantly elevated SBP and DBP at the age of $60(p<0.001 ; p<0.001), 110(p<$ $0.001 ; p<0.01)$ and $130(p<0.01 ; p<0.05)$ days. Also when compared to the LNA rats the LN had increased blood

\section{A}

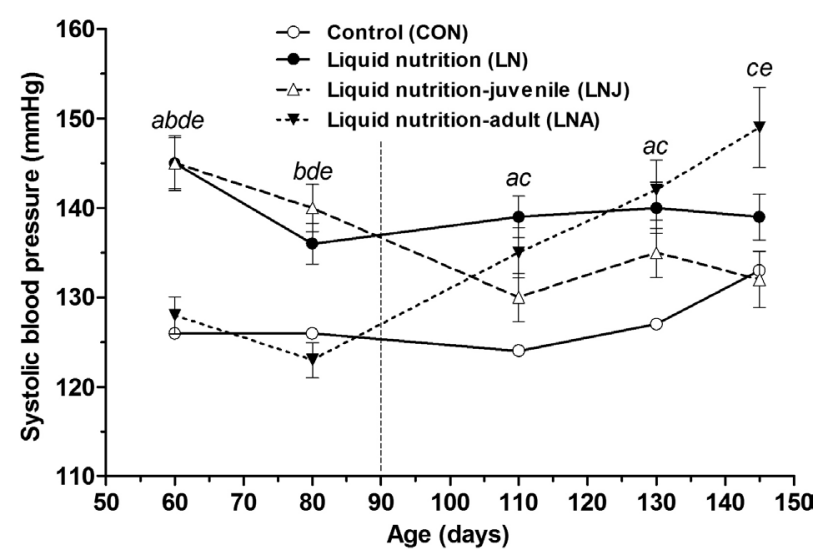

B

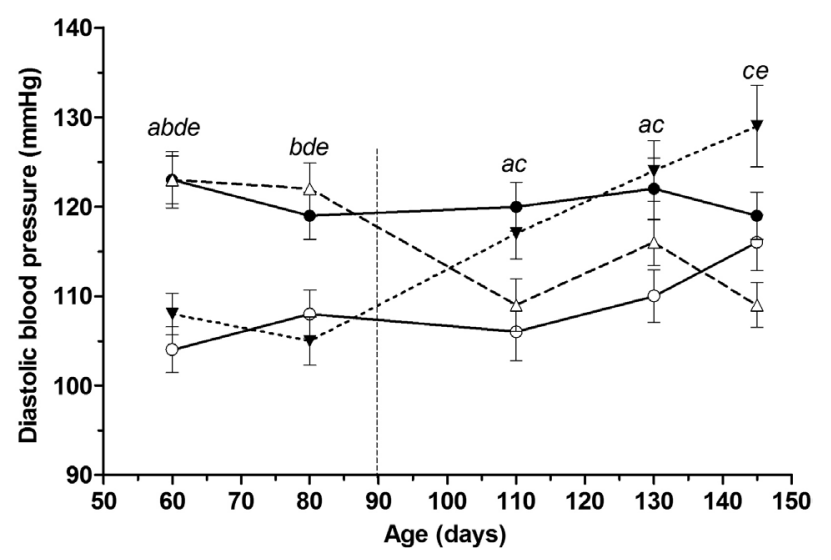

Figure 5. Systolic (A) and diastolic (B) blood pressure of rats fed with pelleted chow (CON), liquid nutrition (LN), liquid nutrition in juvenility (LNJ), or liquid nutrition in adulthood (LNA). Dashed line represents time when diet of LNJ and LNA groups was changed. Each value is expressed as mean \pm SEM ( $n=20$ for each group). Statistical significance between groups (Bonferroni post-tests) $p<0.05$ is indicated by the letters over the values which represent the significant differences between the groups: ${ }^{a} \mathrm{CON}$ vs. LN, ${ }^{\mathrm{b}} \mathrm{CON} v s . \mathrm{LNJ},{ }^{\mathrm{c}} \mathrm{CON} v s . \mathrm{LNA},{ }^{\mathrm{d}} \mathrm{LN}$ vs. LNA, ${ }^{\mathrm{e}} \mathrm{LNJ}$ vs. LNA. pressure with a significance of $p<0.01$ (for SBP and DBP) at the age of 60 days and $p<0.01$ (for SBP and DBP) at the age of 80 days. The liquid nutrition fed LNJ rats had during Fresubin consumption (till 90 days of age) also markedly increased blood pressure compared to the CON rats with $p<$ 0.001 (for both SBP and DBP) at the age of 60 days and $p<$ 0.01 (for both SBP and DBP) at the age of 80 days. They had also significantly increased blood pressure when compared to the LNA rats at the age of 60 days $(p<0.01$ for SBP and DBP) and 80 days $(p<0.001$ for SBP and DBP). After the transfer to chow the blood pressure of LNJ rats decreased to the levels of the CON group. On the contrary, the blood pressure of the LNA rats after the transfer to Fresubin (age 90 days) significantly raised compared to the CON rats (age 110 days $p<0.05$ for SBP and DBP, age 130 days $p<0.001$ for SBP and $p<0.01$ for DBP, age 145 days $p<0.001$ for SBP and $p<0.05$ for DBP) and LNJ rats (age 145 days $p<0.001$ for SBP and DBP; Fig. 5A,B).

In summary, Fresubin consumption led to markedly elevated blood pressure in all by Fresubin fed experimental groups (LN, LNJ, LNA); however, in the LNJ group this increase was temporary only during period of Fresubin consumption.

\section{Organs and tissue weight}

After the weight assessment of the selected organs increased kidney weight was in the Fresubin fed LNA rats observed after comparing to the pelleted chow fed LNJ rats $(p<0.05$; Tab. 1). Interestingly, after the correction for body weight we found decreased kidney weight in the Fresubin fed LN rats comparing to the pelleted chow fed CON and LNJ rats $(p<$ 0.05 for both groups) as well as decreased kidney weight of the LNA rats after comparing to the CON and LNJ groups ( $p<0.05$ for both groups; Tab. 1).

We observed increased heart and separated left ventricle weight in the Fresubin fed LN rats when compared to the pelleted chow fed CON ( $p<0.05$ for both tissues) and LNJ rats ( $p<0.05$ for left ventricle; Tab. 1). However, after the correction for body weight no significant differences were apparent. Similar were the results in the rats of the LNA group which received Fresubin only in adulthood, increased heart weight and left ventricle weight after comparing to $\mathrm{CON}(p<$ 0.05 for both tissues) and LNJ rats ( $p<0.05$ for both tissues) was found (Tab. 1). After correction for body weight these differences disappeared.

\section{Blood lipid profile}

Rats of LN and LNA groups had significantly elevated serum concentrations of total cholesterol, as well as TGL and VLDL cholesterol after comparing to the pelleted chow fed CON and LNJ groups ( $p<0.05$; Tab. 2$)$. The rats fed with 
Table 1. Weight of organs and tissues (mg or \% of body weight) of rats fed with pelleted chow (CON), liquid nutrition (LN), liquid nutrition in juvenility (LNJ), or liquid nutrition in adulthood (LNA)

\begin{tabular}{|c|c|c|c|c|c|c|}
\hline & \multicolumn{2}{|c|}{ Heart } & \multicolumn{2}{|c|}{ Left ventricle } & \multicolumn{2}{|c|}{ Kidneys } \\
\hline & (mg) & (\%) & (mg) & (\%) & (mg) & (\%) \\
\hline $\mathrm{CON}$ & $1337 \pm 35.17$ & $0.263 \pm 0.008$ & $922.1 \pm 28.54$ & $0.181 \pm 0.006$ & $3142.9 \pm 87.73$ & $0.618 \pm 0.017$ \\
\hline $\mathrm{LN}$ & $1463.7 \pm 30.17^{\mathrm{af}}$ & $0.256 \pm 0.004$ & $1004.6 \pm 35.02^{f}$ & $0.175 \pm 0.004$ & $3128.7 \pm 81.01$ & $0.547 \pm 0.009^{\mathrm{af}}$ \\
\hline LNJ & $1234.3 \pm 33.2$ & $0.270 \pm 0.003$ & $864.8 \pm 30.96$ & $0.185 \pm 0.004$ & $2903.7 \pm 89.36$ & $0.634 \pm 0.009$ \\
\hline LNA & $1521.1 \pm 23.99^{\mathrm{ce}}$ & $0.250 \pm 0.010$ & $1072.5 \pm 20.01^{\mathrm{ce}}$ & $0.176 \pm 0.006$ & $3338.5 \pm 44.53^{\mathrm{e}}$ & $0.550 \pm 0.021^{\mathrm{ce}}$ \\
\hline
\end{tabular}

Each value is expressed as mean \pm SEM ( $n=12$ for each group). Statistical significance between groups $p<0.05$ is indicated by the letters over the values which represent the significant differences between the groups: ${ }^{\mathrm{a}} \mathrm{CON} v s . \mathrm{LN},{ }^{\mathrm{c}} \mathrm{CON} v s . \mathrm{LNA},{ }^{\mathrm{e}} \mathrm{LNJ} v s . \mathrm{LNA},{ }^{\mathrm{f}} \mathrm{LN}$ vs. LNJ.

Fresubin only during their juvenility (LNJ) had similar levels of studied lipids compared to control rats (Tab. 2).

\section{Biochemical serum and urine parameters}

In LN and LNA rats we found significantly decreased potassium ions concentrations in the serum $(p<0.05)$ and markedly elevated levels of serum proteins when compared with the animals of CON and LNJ group ( $p<0.05$ for both; Tab. 3 ). Conversely, the urine levels of potassium ions, creatinine and proteins were in LN and LNA animals significantly decreased $(p<0.05$ for all parameters; Tab. 4$)$.

\section{Heart and thoracic aorta morphology}

Significantly increased diameter of cardiomyocytes as well as length of their nuclei was found in the LN group compared to all other groups ( $p<0.05$; Fig. 6A,C; Fig. 7). Compared to the control group animals in the other experimental groups receiving Fresubin either permanently (LN) or during a restricted time period (LNJ, LNA), cardiomyocyte nuclei diameter had significantly increased ( $p<0.05$, Fig. 6B).

No differences were found in the wall thickness of the two measured layers of thoracic aorta, the tunica intima and tunica media among the groups (Fig. 6D, Fig. 8).

\section{Kidney morphology}

In animals receiving Fresubin throughout the experiment (LN group), as well as in animals fed by Fresubin only in adulthood (LNA group) a significant enlargement in the area $(p<0.05)$ and diameter $(p<0.005)$ of renal corpuscles was observed compared to rats fed with pelleted chow throughout the experiment (CON group) and animals fed

Table 2. Serum concentrations of total cholesterol, triglycerides (TGL), and very low density cholesterol (VLDL) in rats fed with pelleted chow (CON), liquid nutrition (LN), liquid nutrition in juvenility (LNJ), or liquid nutrition in adulthood (LNA)

\begin{tabular}{lccc}
\hline Groups & $\begin{array}{c}\text { Total cholesterol } \\
(\mathrm{mmol} / \mathrm{l})\end{array}$ & \multicolumn{1}{c}{$\begin{array}{c}\text { TGL } \\
(\mathrm{mmol} / \mathrm{l})\end{array}$} & $\begin{array}{c}\text { VLDL cholesterol } \\
(\mathrm{mmol} / \mathrm{l})\end{array}$ \\
\hline CON & $1.535 \pm 0.051$ & $1.265 \pm 0.092$ & $0.575 \pm 0.042$ \\
LN & $2.451 \pm 0.053^{\text {af }}$ & $3.103 \pm 0.402^{\text {af }}$ & $1.410 \pm 0.183^{\text {af }}$ \\
LNJ & $1.545 \pm 0.067$ & $1.316 \pm 0.087$ & $0.599 \pm 0.039$ \\
LNA & $2.046 \pm 0.13^{\text {ce }}$ & $3.568 \pm 0.364^{\text {ce }}$ & $1.621 \pm 0.166^{\text {ce }}$ \\
\hline
\end{tabular}

Each value is expressed as mean \pm SEM ( $n=20$ for each group). Statistical significance between groups: $p<0.05$ is indicated by the letters over the values which represent the significant differences between the groups: ${ }^{\mathrm{a}} \mathrm{CON} v s . \mathrm{LN},{ }^{\mathrm{C}} \mathrm{CON} v s . \mathrm{LNA},{ }^{\mathrm{e}} \mathrm{LNJ} v s$. LNA, ${ }^{\mathrm{f}}$ LN vs. LNJ.

Table 3. Serum concentrations of $\mathrm{Na}^{+}, \mathrm{K}^{+}$, creatinine, and proteins in rats fed with pelleted chow (CON), liquid nutrition (LN), liquid nutrition in juvenility (LNJ), or liquid nutrition in adulthood (LNA)

\begin{tabular}{lcccc}
\hline Groups & $\begin{array}{c}\mathrm{Na}^{+} \\
(\mathrm{mmol} / \mathrm{l})\end{array}$ & $\begin{array}{c}\mathrm{K}^{+} \\
(\mathrm{mmol} / \mathrm{l})\end{array}$ & $\begin{array}{c}\text { Creatinine } \\
(\mu \mathrm{mol} / \mathrm{l})\end{array}$ & $\begin{array}{c}\text { Proteins } \\
(\mathrm{g} / \mathrm{l})\end{array}$ \\
\hline CON & $144.805 \pm 0.621$ & $6.761 \pm 0.208$ & $56.700 \pm 2.133$ & $62.705 \pm 0.919$ \\
LN & $146.405 \pm 0.914$ & $5.910 \pm 0.136^{\mathrm{a}}$ & $56.895 \pm 1.915$ & $70.700 \pm 0.829^{\text {af }}$ \\
LNJ & $145.605 \pm 0.528$ & $6.553 \pm 0.194$ & $53.550 \pm 1.702$ & $62.330 \pm 0.650$ \\
LNA & $144.274 \pm 0.669$ & $5.551 \pm 0.149^{\mathrm{ce}}$ & $53.053 \pm 2.342$ & $68.195 \pm 0.802^{\text {ce }}$ \\
\hline
\end{tabular}

Each value is expressed as mean \pm SEM ( $n=20$ for each group). Statistical significance between groups: $p<0.05$ is indicated by the letters over the values which represent the significant differences between the groups: ${ }^{\mathrm{a}} \mathrm{CON} v s . \mathrm{LN},{ }^{\mathrm{c}} \mathrm{CON} v s . \mathrm{LNA},{ }^{\mathrm{e}} \mathrm{LNJ} v s . \mathrm{LNA},{ }^{\mathrm{f}} \mathrm{LN}$ vs. LNJ. 
Table 4. Urine concentrations of $\mathrm{Na}^{+}, \mathrm{K}^{+}$, creatinine, and proteins in rats fed with pelleted chow (CON), liquid nutrition (LN), liquid nutrition in juvenility (LNJ), or liquid nutrition in adulthood (LNA)

\begin{tabular}{lcccc}
\hline Groups & $\begin{array}{c}\mathrm{Na}^{+} \\
(\mathrm{mmol} / \mathrm{l})\end{array}$ & $\begin{array}{c}\mathrm{K}^{+} \\
(\mathrm{mmol} / \mathrm{l})\end{array}$ & $\begin{array}{c}\text { Creatinine } \\
(\mu \mathrm{mol} / \mathrm{l})\end{array}$ & $\begin{array}{c}\text { Proteins } \\
(\mathrm{g} / \mathrm{l})\end{array}$ \\
\hline CON & $52.06 \pm 6.76$ & $272.08 \pm 39.51^{a c}$ & $6373.26 \pm 2092.52^{a}$ & $1.22 \pm 0.18^{a c}$ \\
LN & $35.52 \pm 4.85$ & $29.20 \pm 4.46$ & $1531.80 \pm 229.75$ & $0.18 \pm 0.01$ \\
LNJ & $51.00 \pm 3.06$ & $298.26 \pm 22.87^{e f}$ & $8825.80 \pm 1085.75^{e f}$ & $1.48 \pm 0.22^{\text {ef }}$ \\
LNA & $34.00 \pm 4.53$ & $28.58 \pm 3.82$ & $1390.20 \pm 245.37$ & $0.22 \pm 0.03$ \\
\hline
\end{tabular}

Each value is expressed as mean $\pm \operatorname{SEM}(n=20$ for each group). Statistical significance between groups: $p<0.05$ is indicated by the letters over the values which represent the significant differences between the groups: ${ }^{\mathrm{a}} \mathrm{CON} v s . \mathrm{LN},{ }^{\mathrm{C}} \mathrm{CON} v s . \mathrm{LNA},{ }^{\mathrm{e}} \mathrm{LNJ} v s$. LNA, ${ }^{\mathrm{f}} \mathrm{LN} v s$. LNJ.

with pelleted chow only in adulthood (LNJ group; Fig. 9A,B; Fig. 10). The most enlarged corpuscles were found in the LNA rats. No differences were found between the CON and LNJ group.

\section{Discussion}

Several studies showed that exposure of laboratory animals to liquid nutrition (Ensure) as a diet supplement (Levin and
Keesey 1998; Levin 1999; Levin and Dunn-Meynell 2002; Archer et al. 2005; Archer et al. 2007; Marco et al. 2009) led to the development of an obese phenotype. Because obesity represents a risk factor for the development of hypertension, we investigated the effect of liquid nutrition on body weight as well as blood pressure in rats fed by liquid nutrition (Fresubin). In contrast to studies employing liquid nutrition only as a diet supplementation, in our experiment Fresubin was provided as a fully replacement of standard pelleted chow either throughout the experiment or during selected developmental stages.
A

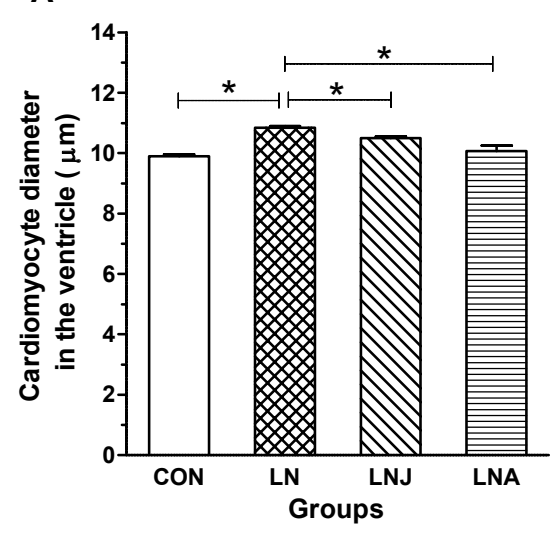

C

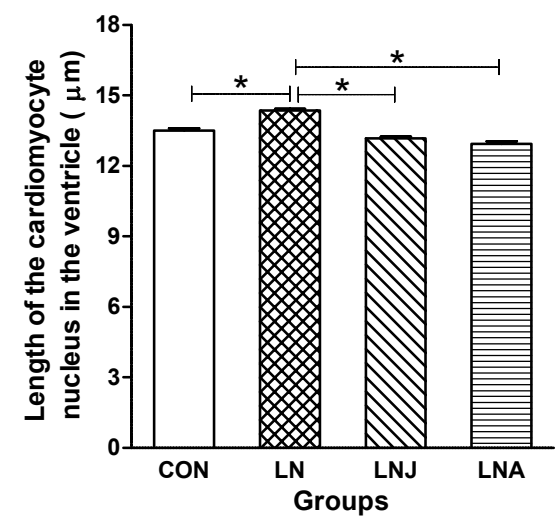

B

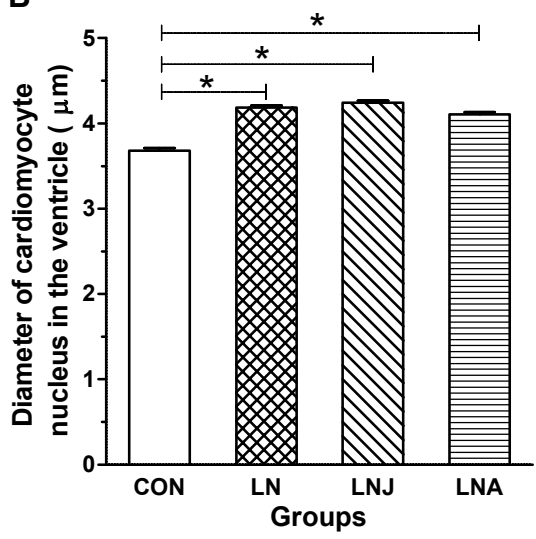

D

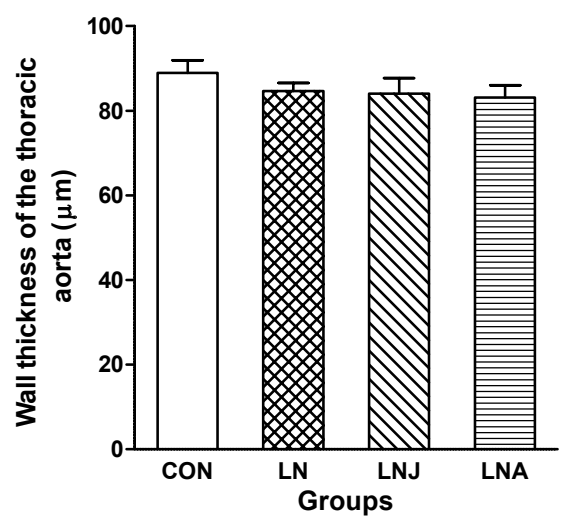

Figure 6. Cardiomyocyte diameter in the ventricle (A), diameter of cardiomyocyte nuclei (B), length of cardiomyocyte nuclei (C), and wall thickness of the thoracic aorta (tunica intima and tunica media) (D) of rats fed with pelleted chow (CON), liquid nutrition (LN), liquid nutrition in juvenility (LNJ), or liquid nutrition in adulthood (LNA). Each value is expressed as mean \pm SEM ( $n=8$ for each group). Statistical significance between groups: ${ }^{\star} p<$ 0.05 . 

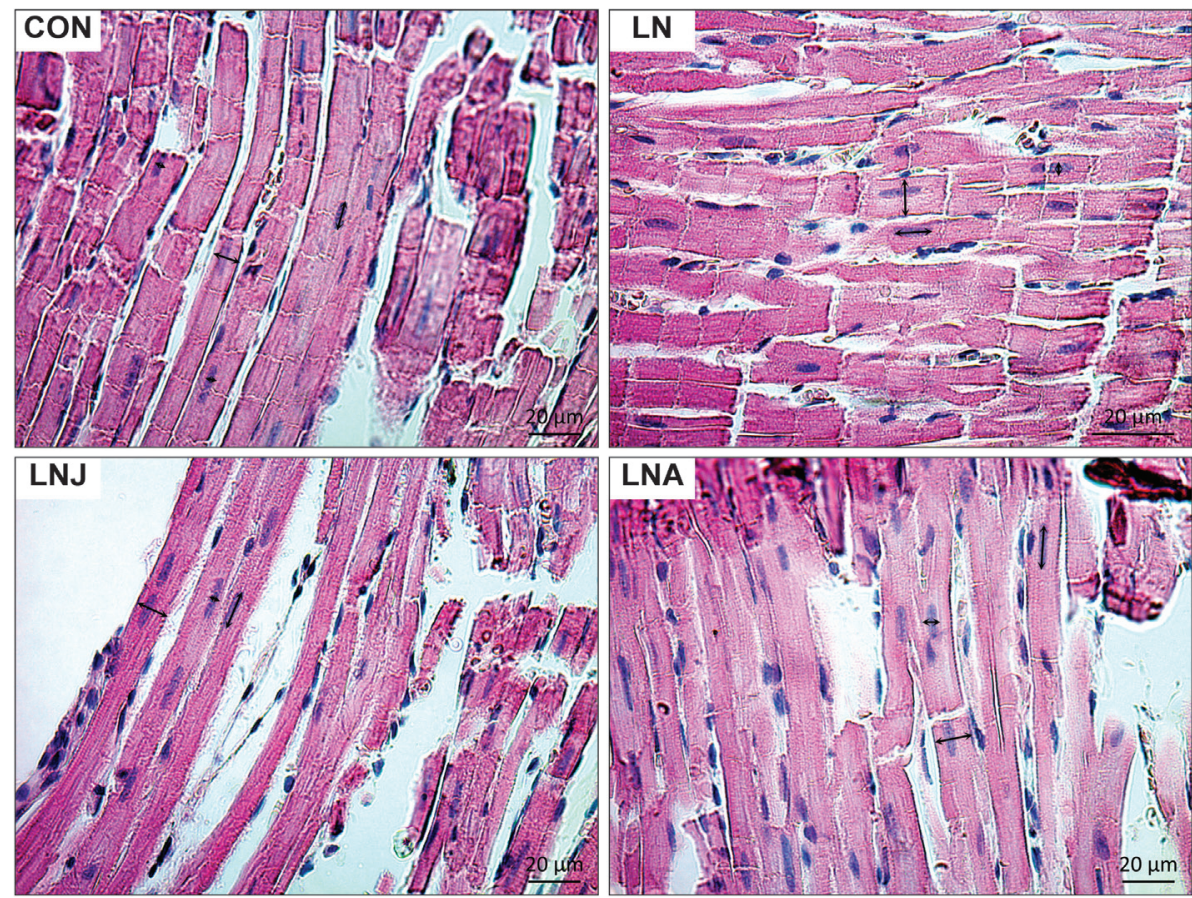

Figure 7. Micrographs of left ventricle are showing the way how cardiomyocyte diameter, cardiomyocyte nuclei diameter and cardiomyocyte nuclei length were measured in rats fed with pelleted chow (CON), liquid nutrition (LN), liquid nutrition in juvenility (LNJ), or liquid nutrition in adulthood (LNA). The structures were visualized by Hematoxylin and eosin staining method at a magnification $\times 400$. Scale bar $20 \mu \mathrm{m}$.

At the age of 60 days the LN and LNJ rats had significantly lowered body weight when compared to the control rats (19.5\%, respectively $18.2 \%)$. A similar phenomenon was observed also by Archer and colleagues, where juvenile rats manifested a phenotype of reduced body weight but increased adiposity after feeding a solid high-energy diet. They speculated that this was due the relatively low protein content (15\%) of the diet and led to overconsumption that only is able to meet the demands of growing rats (Archer et al. 2007). Interestingly the body weight of the LN group

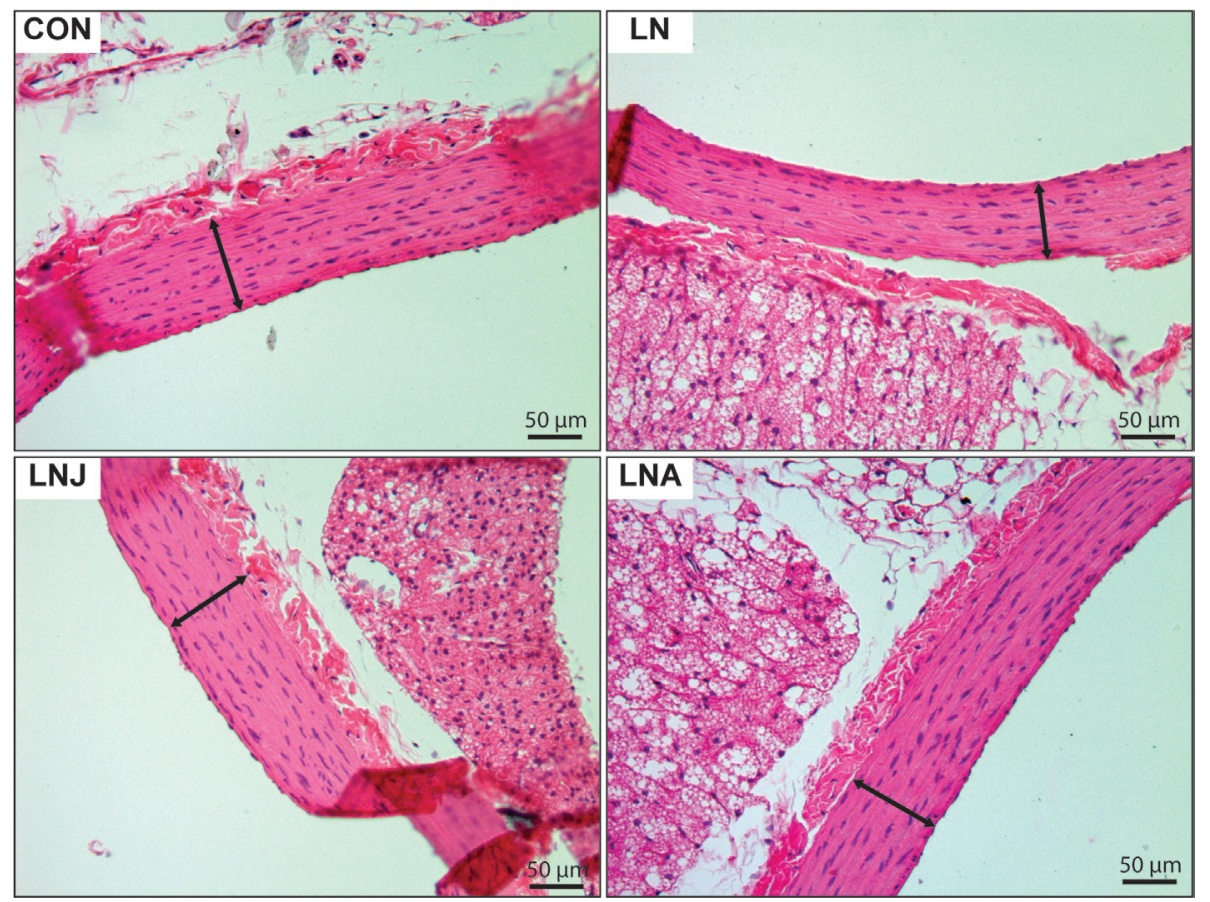

Figure 8. Micrographs of thoracic aorta are showing the way how wall thickness of tunica intima and tunica media were measured in rats fed with pelleted chow $(\mathrm{CON})$, liquid nutrition (LN), liquid nutrition in juvenility (LNJ), or liquid nutrition in adulthood (LNA). The structures were visualized by Hematoxylin and eosin staining method at a magnification $\times 100$. Scale bar $50 \mu \mathrm{m}$. 


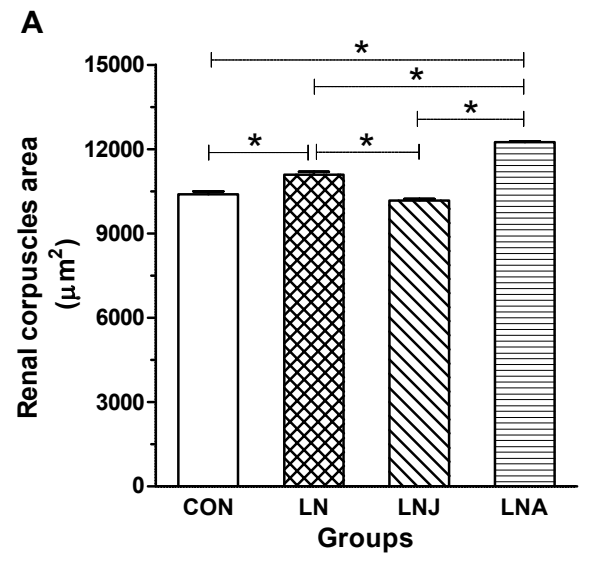

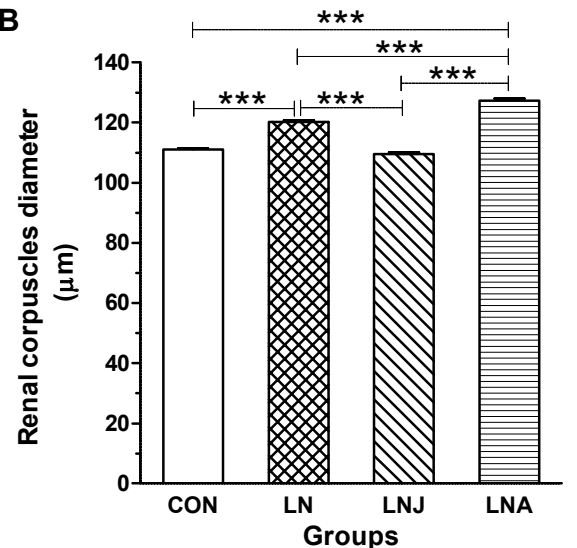

Figure 9. Mean area of renal corpuscles $(\mathbf{A})$ and diameter of renal corpuscles (B) of rats fed with pelleted chow (CON), liquid nutrition (LN), liquid nutrition in juvenility (LNJ), or liquid nutrition in adulthood (LNA). Each value is expressed as mean $\pm \operatorname{SEM}$ ( $n=8$ for each group). Statistical significance between groups: ${ }^{\star} p<0.05,{ }^{* * *} p<0.005$. rose after the rats reached adulthood (age 90 days) and since 130 days of age their body weight was approximately by $16 \%$ higher after comparing to the chow fed control animals. The LNJ rats had after the transfer to pelleted chow (90 days of age) similar body weight like the controls during the whole study. The body weight of the LNA group also rose after the transition to Fresubin and at the end of the study the weight difference after comparing to $\mathrm{CON}$ was represented by $25.5 \%$.

Several indicators of obesity including body weight gain, abdomen circumference, BMI, and Lee index were assessed in the 4 experimental groups and all were significantly higher in the Fresubin fed LN and LNA rats confirming the development of an obese phenotype when compared to chow fed CON and LNJ rats. According to the study of Novelli and colleagues the normal BMI for adult male Wistar rats fed a standard chow diet is in the range between 0.45 and $0.68 \mathrm{~g} / \mathrm{cm}^{2}$ (Novelli et al. 2007). The depositions of abdominal adipose tissue reflected in increased abdominal circumference are important components in the development of obesity related dyslipidemia, hyperglycemia, and hypertension (Kershaw and Flier 2004).

We suggest that the over-consumption leading to obesity observed in Fresubin fed rats documented previously (Mikuska et al. 2013), might be palatability driven and/or related to less induction of satiety signals due its liquidity
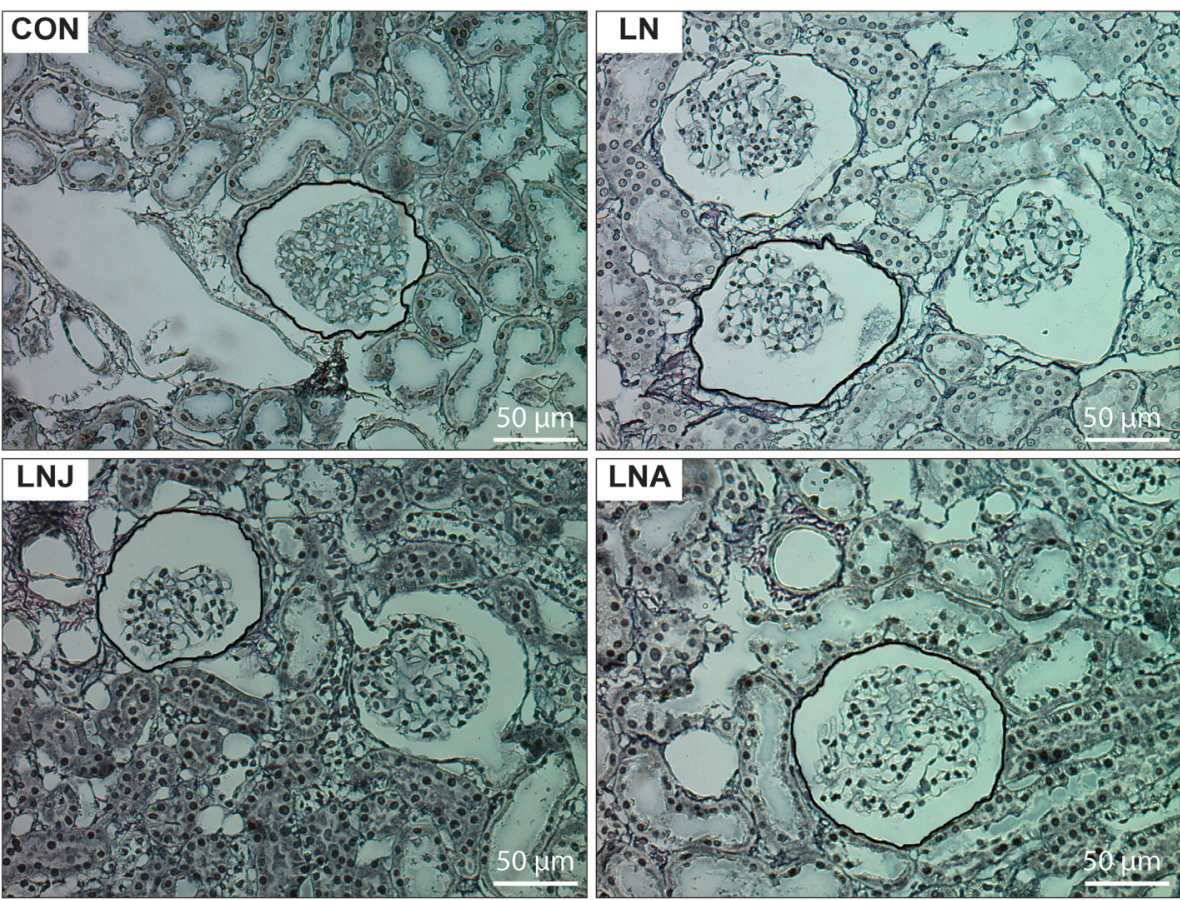

Figure 10. Micrographs of renal cortex are showing the way how renal corpuscle area was measured in rats fed with pelleted chow (CON), liquid nutrition (LN), liquid nutrition in juvenility (LNJ), or liquid nutrition in adulthood (LNA). The structures were visualized by Gomori's impregnation method modified by Lilie at a magnification $\times 200$. Selected renal corpuscles are traced by black. Scale bar $50 \mu \mathrm{m}$. 
and high water content (75\%). Levin, who introduced the model of diet-induced obesity using the supplementation with highly palatable liquid nutrition Ensure, stated that this diet overrides the homeostatic controls of ingestion through the activation of neural systems mediating reward and motivation (Levin 2005). Also other authors reported that diet-induced obesity is the result of the combination of several factors, like hyperphagia, unbalanced macronutrient profile, high energy content, or post-ingestive effects (Archer and Mercer 2007; Hariri and Thibault 2010). It is known, that the consumption of energy-containing fluids leads to less satiety than that of solids of equivalent energy content (DiMeglio and Mattes 2000). We could speculate that the accelerated passage of the liquid food in the gastrointestinal tract leads to inadequate anorexigenic signaling failing to inhibit food intake. Moreover, increased water load might via dilution of plasma result in decreased concentration of anorexigenic signal molecules in circulation. High water intake connected with polyuria seen in our experiment (data not shown) might lead to decreased concentrations of vasopressin in plasma, which is according to Langhans and colleagues associated with decreased inhibition of food intake (Langhans et al. 1991).

We found that exposure of rats to Fresubin exerts a significant effect on blood pressure resulting in markedly elevated systolic and diastolic blood pressure. However, as seen in the LNJ group this effect was only temporary and was limited to the period of Fresubin consumption, as after the transition to the pelleted chow diet the blood pressure values normalized. We suppose, that the increase in blood pressure of Fresubin fed rats is not directly related to weight gain, as the LNJ and LN rats had till 90 days of age despite lower body weight significantly higher blood pressure when compared to the pelleted chow fed control rats. It is also apparent that the blood pressure of the obese LN rats plateaued despite increasing body weight throughout adulthood. We suggest that an interaction between different factors, such the macronutrient composition of the used diet with high carbohydrate and water content, increased sympathetic nervous system activity and hyperleptinemia seems to be involved and contribute to increased blood pressure. Jackson et al. (2012) examined the effects of pre- and postnatal overnutrition with high-fat/high-fructose diet in male Sprague-Dawley rats on blood pressure but they did not find any significant changes even after 17 weeks of diet treatment (Jackson et al. 2012). Also Nascimento and colleagues (2011) after 30 weeks of high-fat diet feeding in rats found no differences in blood pressure of control and obese rats measured by the tail-cuff method (Nascimento et al. 2011). Similarly, the results of Carroll et al. (2006) showed that 12 weeks of moderate fat diet in obesity-prone/obesity-resistant rats induces lipid and endocrine abnormalities which are typical for obesity, but not significant cardiac abnormalities. On the other hand, Dobrian et al. (2000) observed significantly elevated systolic blood pressure measured with tail-cuff method in Sprague-Dawley rats provided a diet containing 32\% fat for 10 weeks. This discrepancy between our study and others might be explained by the different rat strains and types of the diet used. We suggest that the high water content of Fresubin resulted in high water load which could be reflected in higher blood pressure. However, according to Hal (2003), over a long period of increased water intake there must be a precise balance between intake and water excretion and chronic hypertension cannot develop unless there is a shift of renal-pressure natriuresis to higher blood pressures.

El-Atat et al. (2004) reported that increased food intake, primarily, fat and carbohydrates, increases sympathetic nervous system (SNS) activity. As Fresubin contains of 55\% carbohydrates it could lead to increased sympathetic activity that may partially explain the observed increase of blood pressure. This hypothesis is also strengthened by studies suggesting that overeating and weight gain are responsible for sympathetic overactivity (Baba et al. 2007).

Several studies also suggested that overfed or high-fat fed rats as well as genetically obese (fa/fa) Zucker rats overrespond to acute stressors (Pascoe et al. 1991; Balkan et al. 1993; Levin et al. 2000). It is possible, that the non-invasive blood pressure measurement carried out by the tail-cuff method despite the habituation and adaptation process was perceived as a stressor by the rats. So the increased blood pressure in rats fed by Fresubin was the result of their higher reactivity and responsiveness to handling stress. This issue could be elucidated by using telemetric devices for blood pressure measurements. Also other authors suggested that the tail-cuff method may be susceptible to errors as obese rats have exhibited an enhanced response to stress; however, this is by no means universal (McArthur et al. 1998; Sedova et al. 2004).

It was shown that adipokines acts on several fields, including the regulation of appetite, glucose and lipid metabolism, blood pressure, and inflammation (Balistreri et al. 2010). Shek et al. (1998) demonstrated despite marked hypophagia and weight loss in rats a sustained increase in blood pressure due to leptin infusions (Shek et al. 1998). It is possible that hyperleptinemia affected the blood pressure of rats fed with Fresubin, as increased levels of circulating leptin were by radioimmunoassay assessed in all Fresubin fed groups (LN, LNJ, LNA; data not shown). At the age of 2 months in Fresubin fed LNJ group plasma leptin levels were higher by $99 \%$ and in the LN group by $72 \%$ compared to the pelleted chow fed control rats. At the age of 4 months the increase in LN group was by $285 \%$ and in the LNA group by $206 \%$. Previously Mark et al. (1999) showed that leptin deficient obese mice and obese rats with leptin receptor mutations have little or no hypertension compared with lean animals. Rahmouni et al. (2005) described that obese mice fed high-fat diet for 
10 weeks exhibit circulating hyperleptinemia and resistance to metabolic actions of leptin, however the renal sympathetic and arterial pressure responses to leptin are preserved. These observations point towards leptin as a potential mediator of obesity-related hypertension and the pathophysiologic significance of selective leptin resistance.

Hypertension in obese individuals is frequently associated with dyslipidaemia, particularly with low levels of HDLcholesterol and increased levels of TGL (Dobrian et al. 2000). A pro-atherogenic blood profile with signs of dyslipidaemia (increased total cholesterol, TGL and VLDL cholesterol) in serum of LN and LNA rats was observed probably due to increased weight, respectively obesity. As we reported above, at the end of our experiment body weight gain of LN rats was represented by $16 \%$ and of that of LNA rats by $25.5 \%$ compared to the CON rats. After 10 weeks of a moderate fat diet Dobrian and colleagues observed increased levels of TGL, total cholesterol, and LDL-cholesterol in rats (Dobrian et al. 2000). Also Carroll et al. (2006) reported significantly elevated plasma and hepatic cholesterol in their model of diet-induced obesity associated with increased systolic blood pressure. In addition, hypertension along with hyperlipidemia may induce glomerulosclerosis and possibly alter kidney function (Dobrian et al. 2000). However, this issue is still controversial. Many studies have shown that dyslipidaemia can contribute to renal injury (Fried et al. 2001; Praga 2002). On the other hand Jiang et al. (2005) in their high-fat diet-induced obesity model in mice showed that glomerulosclerosis and proteinuria were present without changes in plasma TGL, cholesterol, and free fatty acid levels. Also Stemmer et al. (2012) have suggested that lipotoxicity is not a critical contributor to renal pathology, as they found similar plasma TGL, free fatty acids, and renal TGL in chowfed and diet-induced obesity resistant and sensitive rats.

The consumption of liquid nutrition Fresubin in our experiment did not lead either to heart or left ventricle hypertrophy, or to histological alterations in the thoracic aorta. These data demonstrate that the used diet protocol and related blood pressure increase was not sufficient to induce profound cardiac abnormalities. Also in the study of Carroll et. al. (2006) heart weight and cardiac collagen amount did not differ among the control rats and diet-induced obese rats. On the contrary, in the earlier mentioned study of Dobrian et al. (2000) increased aortic wall area was observed, indicating arterial hypertrophy. Several factors play role in the genesis of ventricular hypertrophy, including hypertension, volume load, age, salt intake, angiotensin II, and insulin (Carroll et al. 2006). We can speculate that in $\mathrm{LN}$ rats the increased cardiomyocyte diameter (by $9.5 \%$ compared to CON), cardiomyocyte nucleus diameter (by $13.7 \%$ compared to CON), and length (by 6.3\% compared to $\mathrm{CON}$ ) could indicate primary symptoms of starting cardiac hypertrophy.
We found increased size of renal corpuscles in both groups of Fresubin fed adult rats, however, it didn't lead to hypertrophy of the kidney. In the LNJ the size of renal corpuscles was not altered compared to the control animals. In the LN rats increased mean corpuscle area by $6.8 \%$ and mean corpuscle diameter by $8.3 \%$ was found and in the LNA increased mean corpuscle area by $17.9 \%$ and mean corpuscle diameter by $14.6 \%$ compared to CON was observed. These histological alterations may result from prolonged intake of liquid nutrition accompanied by marked water load but also from obesity connected with hypertension and hyperinsulinemia (data not shown). We assessed circulating insulin levels in all the 4 groups of rats by radioimmunoassay. At the age of 4 months in the Fresubin fed LN rats by $173 \%$ and in the LNA rats by $116 \%$ higher insulin levels were found when compared to the chow fed control rats. Our findings regarding hyperinsulinemia are in accordance with the study results of Levin et. al. (2000) who reported increased circulating insulin levels in diet-induced obese rats fed over 10 weeks a high energy diet supplemented with the palatable liquid nutrition Ensure (Levin and Dunn-Meynell 2002). Cusumano et al. (2002) pointed out that there exists a link between hyperinsulinemia and glomerular hypertrophy in rhesus monkeys with increased glomerular size before the onset of diabetes. So, there could be a link between increased renal corpuscles and hyperinsulinemia and/or increased water load in liquid nutrition fed obese rats.

We suggest that the renal functions of Fresubin fed rats were not affected, as in LN and LNA rats were present either, proteinuria, natriuresis, increased levels of potassium ions or creatinine in urine and serum. Hypothetically, since Fresubin was a "low protein diet" (Mikuska et al. 2013) where proteins represented $15 \%$, it does not represent ballast on the kidneys. Increased water load offset by increased urination resulted in decreased urine creatinine, potassium and protein concentrations found in Fresubin fed rats.

\section{Conclusion}

Our study shows that chronic intake of liquid nutrition Fresubin can significantly increase body weight and blood pressure, alter the lipid spectrum in the plasma, and histological features of renal corpuscles and cardiomyocytes in the Wistar rats. However, these changes are dependent on the developmental stage during which liquid nutrition is provided. It seems that intake of liquid nutrition only in juvenile period does not induce any significant histological changes in heart and kidney persisting until adulthood, and the blood pressure increase was also dependent on Fresubin consumption, moreover it was shown to be reversible. We suggest that the used diet was the major factor that caused 
hypertension, not obesity itself. Fresubin consumption also/ or only in adulthood led to immediate increase in body weight, blood pressure and caused histological alterations of the kidneys and cardiomyocytes.

The mechanisms connecting Fresubin intake and increase of blood pressure in rats were not fully elucidated in our study. We suppose that this phenomenon is independent of weight gain and subsequent obesity, but there are several other mechanisms and their combinations which could play important role. These may include especially liquidity of the diet and high water content, but also macronutrient composition with higher carbohydrate content, hyperleptinemia, increased sympathetic activity, and higher responsiveness to stress. Therefore further research is necessary to elucidate the link between increased intake of liquid foods and development of hypertension.

Acknowledgements. This research was supported by the Slovak Research and Development Agency (APVV-0434-12) and European Regional Development Fund Research and Development Grant (ITMS 26240120015). The grant support had no role in the design, analysis or writing of this article.

Conflict of interest. The authors declare that there are no conflicts of interests.

\section{References}

Altunkaynak M. E., Ozbek E., Altunkaynak B. Z., Can I., Unal D., Unal B. (2008): The effects of high-fat diet on the renal structure and morphometric parametric of kidneys in rats. J. Anat. 212, 845-852 http://dx.doi.org/10.1111/j.1469-7580.2008.00902.x

Archer Z. A., Rayner D. V., Barrett P., Balik A., Duncan J. S., Moar K. M., Mercer J. G. (2005): Hypothalamic energy balance gene responses in the Sprague-Dawley rat to supplementation of high-energy diet with liquid ensure and subsequent transfer to chow. J. Neuroendocrinol. 17, 711-719 http://dx.doi.org/10.1111/j.1365-2826.2005.01363.x

Archer Z. A., Corneloup J., Rayner D. V., Barrett P., Moar K. M., Mercer J. G. (2007): Solid and liquid obesogenic diets induce obesity and counter-regulatory changes in hypothalamic gene expression in juvenile Sprague-Dawley rats. J. Nutr. 137, $1483-1490$

Archer Z. A., Mercer J. G. (2007): Brain responses to obesogenic diets and diet-induced obesity. Proc. Nutr. Soc. 66, 124-130 http://dx.doi.org/10.1017/S0029665107005356

Baba R., Koketsu M., Nagashima M., Inasaka H., Yoshinaga M., Yokota M. (2007): Adolescent obesity adversely affects blood pressure and resting heart rate. Circ. J. 71, 722-726 http://dx.doi.org/10.1253/circj.71.722

Bagby S. P. (2004): Obesity-initiated metabolic syndrome and the kidney: a recipe for chronic kidney disease? J. Am. Soc. Nephrol. 15, 2775-2791 http://dx.doi.org/10.1097/01.ASN.0000141965.28037.EE
Balistreri C. R., Caruso C., Candore G. (2010): The role of adipose tissue and adipokines in obesity-related inflammatory diseases. Mediators Inflamm. 2010, 802078 http://dx.doi.org/10.1155/2010/802078

Balkan B., Strubbe J. H., Bruggink J. E., Steffens A. B. (1993): Overfeeding-induced obesity in rats: insulin sensitivity and autonomic regulation of metabolism. Metabolism 42, 1509-1518 http://dx.doi.org/10.1016/0026-0495(93)90144-D

Bernardis L. L., Patterson B. D. (1968): Correlation between ,Lee index' and carcass fat content in weanling and adult female rats with hypothalamic lesions. J. Endocrinol. 40, 527-528 http://dx.doi.org/10.1677/joe.0.0400527

Boustany C. M., Brown D. R., Randall D. C., Cassis L. A. (2005): AT1-receptor antagonism reverses the blood pressure elevation associated with diet-induced obesity. Am. J. Physiol. Regul. Integr. Comp. Physiol. 289, R181-186 http://dx.doi.org/10.1152/ajpregu.00507.2004

Carroll J. F., Zenebe W. J., Strange T. B. (2006): Cardiovascular function in a rat model of diet-induced obesity. Hypertension $48,65-72$ http://dx.doi.org/10.1161/01.HYP.0000224147.01024.77

Cusumano A. M., Bodkin N. L., Hansen B. C., Iotti R., Owens J., Klotman P. E., Kopp J. B. (2002): Glomerular hypertrophy is associated with hyperinsulinemia and precedes overt diabetes in aging rhesus monkeys. Am. J. Kidney Dis. 40, 1075-1085 http://dx.doi.org/10.1053/ajkd.2002.36348

DiMeglio D. P., Mattes R. D. (2000): Liquid versus solid carbohydrate: effects on food intake and body weight. Int. J. Obes. Relat. Metab. Disord. 24, 794-800 http://dx.doi.org/10.1038/sj.ijo.0801229

Dobrian A. D., Davies M. J., Prewitt R. L., Lauterio T. J. (2000): Development of hypertension in a rat model of diet-induced obesity. Hypertension 35, 1009-1015 http://dx.doi.org/10.1161/01.HYP.35.4.1009

Dobrian A. D., Schriver S. D., Khraibi A. A., Prewitt R. L. (2004): Pioglitazone prevents hypertension and reduces oxidative stress in diet-induced obesity. Hypertension 43, 48-56 http://dx.doi.org/10.1161/01.HYP.0000103629.01745.59

El-Atat F. A., Stas S. N., McFarlane S. I., Sowers J. R. (2004): The relationship between hyperinsulinemia, hypertension and progressive renal disease. J. Am. Soc. Nephrol. 15, 2816-2827 http://dx.doi.org/10.1097/01.ASN.0000133698.80390.37

Farah M. C., Castro C. R., Moreira V. M., Riso Ade A., Lopes A. A., Aiello V. D. (2009): The myocardium in tetralogy of Fallot: a histological and morphometric study. Arq. Bras. Cardiol. 92, 160-167, 163-171

Fried L. F., Orchard T. J., Kasiske B. L. (2001): Effect of lipid reduction on the progression of renal disease: a meta-analysis. Kidney Int. 59, 260-269 http://dx.doi.org/10.1046/j.1523-1755.2001.00487.x

Hall J. E. (2003): The kidney, hypertension, and obesity. Hypertension 41, 625-633

http://dx.doi.org/10.1161/01.HYP.0000052314.95497.78

Hariri N., Thibault L. (2010): High-fat diet-induced obesity in animal models. Nutr. Res. Rev. 23, 270-299 http://dx.doi.org/10.1017/S0954422410000168

Jackson C. M., Alexander B. T., Roach L., Haggerty D., Marbury D. C., Hutchens Z. M., Flynn E. R., Maric-Bilkan C. (2012): 
Exposure to maternal overnutrition and a high-fat diet during early postnatal development increases susceptibility to renal and metabolic injury later in life. Am. J. Physiol. Renal. Physiol. 302, F774-783

http://dx.doi.org/10.1152/ajprenal.00491.2011

Jiang T., Wang Z., Proctor G., Moskowitz S., Liebman S. E., Rogers T., Lucia M. S., Li J., Levi M. (2005): Diet-induced obesity in C57BL/6J mice causes increased renal lipid accumulation and glomerulosclerosis via a sterol regulatory element-binding protein-1c-dependent pathway. J. Biol. Chem. 280, 32317-32325 http://dx.doi.org/10.1074/jbc.M500801200

Kershaw E. E., Flier J. S. (2004): Adipose tissue as an endocrine organ. J. Clin. Endocrinol. Metab. 89, 2548-2556 http://dx.doi.org/10.1210/jc.2004-0395

Langhans W., Delprete E., Scharrer E. (1991): Mechanisms of vasopressins anorectic effect. Physiol. Behav. 49, 169-176 http://dx.doi.org/10.1016/0031-9384(91)90251-I

Levin B. E., Keesey R. E. (1998): Defense of differing body weight set points in diet-induced obese and resistant rats. Am. J. Physiol. 274, R412-419

Levin B. E. (1999): Arcuate NPY neurons and energy homeostasis in diet-induced obese and resistant rats. Am. J. Physiol. 276, R382-387

Levin B. E., Richard D., Michel C., Servatius R. (2000): Differential stress responsivity in diet-induced obese and resistant rats. Am. J. Physiol. Regul. Integr. Comp. Physiol. 279, R1357-1364

Levin B. E., Dunn-Meynell A. A. (2002): Defense of body weight depends on dietary composition and palatability in rats with diet-induced obesity. Am. J. Physiol. Regul. Integr. Comp. Physiol. 282, R46-54

Levin B. E. (2005): Factors promoting and ameliorating the development of obesity. Physiol. Behav. 86, 633-639 http://dx.doi.org/10.1016/j.physbeh.2005.08.054

Ludwig D. S., Peterson K. E., Gortmaker S. L. (2001): Relation between consumption of sugar-sweetened drinks and childhood obesity: a prospective, observational analysis. Lancet 357, 505-508 http://dx.doi.org/10.1016/S0140-6736(00)04041-1

Malik V. S., Schulze M. B., Hu F. B. (2006): Intake of sugar-sweetened beverages and weight gain: a systematic review. Am. J. Clin. Nutr. 84, 274-288

Mamikutty N., Thent Z. C., Sapri S. R., Sahruddin N. N., Mohd Yusof M. R., Haji Suhaimi F. (2014): The establishment of metabolic syndrome model by induction of fructose drinking water in male Wistar rats. Biomed. Res. Int. 2014, 263897 http://dx.doi.org/10.1155/2014/263897

Marco A., Schroeder M., Weller A. (2009): Microstructural pattern of palatable food intake from weaning to adulthood in male and female OLETF rats. Behav. Neurosci. 123, 1251-1260 http://dx.doi.org/10.1037/a0017740

Mark A. L., Shaffer R. A., Correia M. L., Morgan D. A., Sigmund C. D., Haynes W. G. (1999): Contrasting blood pressure effects of obesity in leptin-deficient ob/ob mice and agouti yellow obese mice. J. Hypertens. 17, 1949-1953 http://dx.doi.org/10.1097/00004872-199917121-00026

McArthur M. D., Graham S. E., Russell J. C., Brindley D. N. (1998): Exaggerated stress-induced release of nonesterified fatty acids in JCR:LA-corpulent rats. Metabolism 47, 1383-1390
http://dx.doi.org/10.1016/S0026-0495(98)90310-9

Mikuska L., Vrabcova M., Lackovicova L., Ukropec J., Hegedusova N., Slavkovsky P., Hubka P., Mravec B. (2013): Long-term liquid nutrition intake and development of obesity: differences between young and adult rats. Endocr. Regul. 47, 85-92 http://dx.doi.org/10.4149/endo_2013_02_85

Nascimento T. B., Baptista Rde F., Pereira P. C., Campos D. H., Leopoldo A. S., Leopoldo A. P., Oliveira S. A. Jr., Padovani C. R., Cicogna A. C., Cordellini S. (2011): Vascular alterations in high-fat diet-obese rats: role of endothelial L-arginine/NO pathway. Arq. Bras. Cardiol. 97, 40-45 http://dx.doi.org/10.1590/S0066-782X2011005000063

Ndisang J. F., Jadhav A. (2010): Heme arginate therapy enhanced adiponectin and atrial natriuretic peptide, but abated endothelin-1 with attenuation of kidney histopathological lesions in mineralocorticoid-induced hypertension. J. Pharmacol. Exp. Ther. 334, 87-98 http://dx.doi.org/10.1124/jpet.109.164871

Noszczyk-Nowak A., Nicpon J., Nowak M., Slawuta P. (2009): Preliminary reference values for electrocardiography, echocardiography and myocardial morphometry in the European brown hare (Lepus europaeus). Acta Vet. Scand. 51, 6 http://dx.doi.org/10.1186/1751-0147-51-6

Novelli E. L., Diniz Y. S., Galhardi C. M., Ebaid G. M., Rodrigues H. G., Mani F., Fernandes A. A., Cicogna A. C., Novelli Filho J. L. (2007): Anthropometrical parameters and markers of obesity in rats. Lab. Anim. 41, 111-119 http://dx.doi.org/10.1258/002367707779399518

Pascoe W. S., Smythe G. A., Storlien L. H. (1991): Enhanced responses to stress induced by fat-feeding in rats: relationship between hypothalamic noradrenaline and blood glucose. Brain Res. 550, 192-196 http://dx.doi.org/10.1016/0006-8993(91)91317-T

Praga M. (2002): Obesity--a neglected culprit in renal disease. Nephrol. Dial. Transplant. 17, 1157-1159 http://dx.doi.org/10.1093/ndt/17.7.1157

Rahmouni K., Morgan D. A., Morgan G. M., Mark A. L., Haynes W. G. (2005): Role of selective leptin resistance in diet-induced obesity hypertension. Diabetes 54, 2012-2018 http://dx.doi.org/10.2337/diabetes.54.7.2012

Sedova L., Berube J., Gaudet D., Dumont M., Tremblay J., Hamet P., Pausova Z. (2004): Diet-induced obesity delays cardiovascular recovery from stress in spontaneously hypertensive rats. Obes. Res. 12, 1951-1958 http://dx.doi.org/10.1038/oby.2004.245

Shek E. W., Brands M. W., Hall J. E. (1998): Chronic leptin infusion increases arterial pressure. Hypertension 31, 409-414 http://dx.doi.org/10.1161/01.HYP.31.1.409

Stemmer K., Perez-Tilve D., Ananthakrishnan G., Bort A., Seeley R. J., Tschop M. H., Dietrich D. R., Pfluger P. T. (2012): Highfat-diet-induced obesity causes an inflammatory and tumorpromoting microenvironment in the rat kidney. Dis. Model Mech. 5, 627-635

http://dx.doi.org/10.1242/dmm.009407

Received: August 12, 2015

Final version accepted: September 28, 2015

First published online: February 18, 2016 